\title{
Energy Dissipation Measurement in Improved Spatial Resolution Under Fatigue Loading
}

\author{
A. Akai $^{1} \cdot$ D. Shiozawa ${ }^{2} \cdot$ T. Yamada $^{2} \cdot$ T. Sakagami $^{2}$
}

Received: 15 May 2019 / Accepted: 30 September 2019/Published online: 28 October 2019

(C) The Author(s) 2019

\begin{abstract}
Recently, a technique for rapidly determining a material's fatigue limit by measuring energy dissipation using infrared thermography has received increasing interest. Measuring the energy dissipation of a material under fatigue loading allows the rapid determination of a stress level that empirically coincides with its fatigue limit. To clarify the physical implications of the rapid fatigue limit determination, the relationship between energy dissipation and fatigue damage initiation process was investigated. To discuss the fatigue damage initiation process at grain size scale, we performed high-spatial-resolution dissipated energy measurements on type 316L austenitic stainless steel, and observed the slip bands on the same side of the specimen. The preprocessing of dissipated energy measurement such as motion compensation and a smoothing filter was applied. It was found that the distribution of dissipated energy obtained by improved spatial resolution measurement pinpointed the location of fatigue crack initiation. Owing to the positive correlation between the magnitude of dissipated energy and number of slip bands, it was suggested that the dissipated energy was associated with the behavior of slip bands, with regions of high dissipated energy predicting the location of fatigue crack initiation.
\end{abstract}

Keywords Dissipated energy $\cdot$ Slip band $\cdot$ Crack initiation $\cdot$ Infrared thermography $\cdot$ Stainless steel

\section{Introduction}

Knowing the fatigue limit of a material is indispensable in structural design; however, its determination by conventional fatigue testing is a time-consuming and costly process. For this reason, studies on the rapid determination of fatigue limit by observing temperature changes have been conducted since the beginning of the $20^{\text {th }}$ century for various materials, structures, and fatigue types [1-24]. Fatigue damage causes local plasticity, which leads to irreversible energy dissipation in the

A. Akai

a-akai@mosk.tytlabs.co.jp

D. Shiozawa

shiozawa@mech.kobe-u.ac.jp

T. Sakagami

sakagami@mech.kobe-u.ac.jp

1 Toyota Central R\&D Labs., Inc., 41-1, Yokomichi, Nagakute, Aichi 480-1192, Japan

2 Kobe University, 1-1, Rokkodai-cho, Nada-ku, Kobe, Hyogo 657-8501, Japan form of heat. In recent years, $2 f$ lock-in thermography has received increasing interest on account of the improved performance of infrared cameras [17]. This technique utilizes the specific temperature increase due to plastic deformation by analyzing the measured temperature signals in a frequency domain [25]. Using two-dimensional thermal images of this specific temperature increase during frequency analysis, a considerable part of fatigue damage can be visualized in the form of hot spots. Hence, the $2 f$ lock-in thermography has the potential to accurately assess the location of fatigue failure $[4$, $10]$ as well as the fatigue limit $[4-8,10,17,18]$. However, although the determined stress level empirically coincides with the fatigue limit of the tested material, the physical implications and validity of the stress level determined in this manner have not been sufficiently clarified $[3,26]$. Hence, it is necessary to investigate the mechanism of energy dissipation in relation to fatigue damage, and to discuss a physical model for the rapid fatigue limit determination. This will improve the reliability of this technique and promote its use in industry.

Various researchers have attempted to understand the mechanism of energy dissipation under fatigue loading. Yang et al. [27], Jiang et al. [28], and Ly et al. [29] simulated the temperature increase due to dissipated energy 


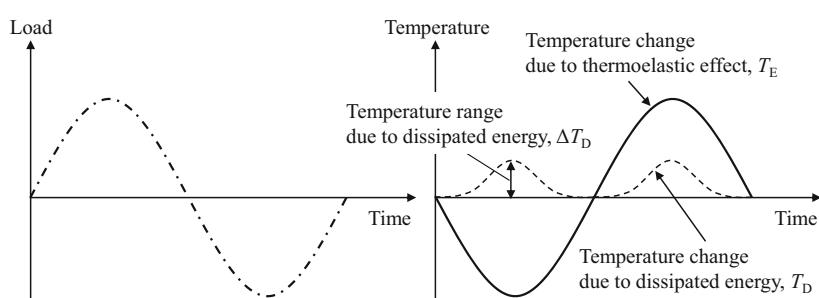

(a) Cyclic loading

(b) Temperature changes due to the thermoelastic effect and dissipated energy

Fig. 1 Schematic illustration of temperature changes due to the thermoelastic effect and dissipated energy measured during cyclic loading

based on plastic strain energy. Boulanger et al. [30], Morabito et al. [31], and Berthel et al. [32] also calculated the heat caused by irreversible energy dissipation via calorimetric analyses. Bodelot et al. [33] and Wang et al. [34] attempted to relate the material deformation behaviors and temperature on the microstructure scale under tensile loading. Bodelot et al. [35] further attempted to relate them at the grain scale under cyclic loading. In the work of Cugy et al. [36], the number of slip bands observed on the specimen surface was found to correlate with the average temperature increase caused by energy dissipation for a low carbon steel. In the work of Wang et al. [37], the relationship between energy dissipation and slip bands was also investigated for an Armco iron. In the works of the author group [38, 39], the growth of slip bands on the specimen surface was observed using atomic force microscopy (AFM) along with dissipated energy measurements for type $316 \mathrm{~L}$ austenitic stainless steel. The number of slip bands, slip distance, and width of slip bands were further evaluated in relation to dissipated energy. However, limitations of the utilized measurement systems meant that these researchers investigated the behavior of slip bands and dissipated energy in different spatial resolutions, in addition to on different sides of the specimen (e.g., the temperature increase was averaged over the entire specimen, and/or the growth of slip bands was investigated on the reverse side to dissipated energy measurements).

Consequently, to relate these two parameters directly, their evaluation must be performed in the same region and on the same scale. In this study, dissipated energy measurements were conducted with high spatial resolution on the same side of the specimen as slip band observations. Moreover, the relationship between the dissipated energy and slip bands was quantitatively evaluated.

Table 1 Chemical composition of the employed material (mass \%)

\begin{tabular}{lllllllll}
\hline $\mathrm{C}$ & $\mathrm{Si}$ & $\mathrm{Mn}$ & $\mathrm{P}$ & $\mathrm{S}$ & $\mathrm{Ni}$ & $\mathrm{Cr}$ & $\mathrm{Mo}$ & $\mathrm{Co}$ \\
\hline 0.011 & 0.65 & 1.18 & 0.035 & 0.002 & 12.18 & 17.36 & 2.06 & 0.22 \\
\hline
\end{tabular}

Table 2 Mechanical properties of the material after solution heat treatment, obtained from tensile testing in accordance with JIS Z 2241:2011 "Metallic materials - Tensile testing-Method of test at room temperature"

\begin{tabular}{lll}
\hline $0.2 \%$ Proof strength & Tensile strength & Elongation \\
\hline $263 \mathrm{MPa}$ & $618 \mathrm{MPa}$ & $85 \%$ \\
\hline
\end{tabular}

\section{Temperature Changes Due to Thermoelastic Effect and Dissipated Energy}

A reversible temperature change is observed for a specimen subjected to cyclic loading. In adiabatic conditions, the well-known thermoelastic effect is observed, where a decrease in temperature is observed under tensile loading, and an increase in temperature is observed under compressive loading.

However, an increase in temperature due to irreversible energy dissipation is observed in addition to the reversible temperature change due to the thermoelastic effect. This temperature increase is caused by local plastic deformation, and occurs significantly at the maximum tensile and compressive loadings [25, 40]. Under sinusoidal tensile and compressive loadings, i.e., the dash-dotted line in Fig. 1 (a), the temperature changes due to the thermoelastic effect $\left(T_{\mathrm{E}}\right)$ and dissipated energy $\left(T_{\mathrm{D}}\right)$ are schematically shown as solid and broken lines in Fig. 1 (b), respectively [17]. As the significant increase in temperature due to dissipated energy occurs twice during one loading cycle, the frequency of the related temperature component is two times greater than that of the loading frequency. In this study, a time-series temperature change of the specimen surface, measured by infrared thermography, was analyzed in the frequency domain. The range of

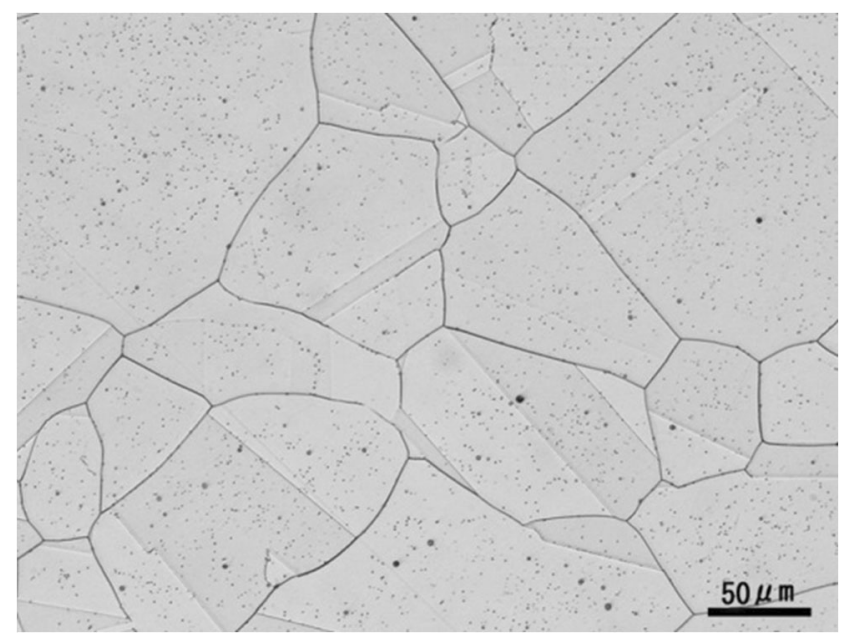

Fig. 2 Micrograph of the material after solution heat treatment. The average grain size is $123 \mu \mathrm{m}$ in accordance with JIS G 0551:2005 "Steels-Micrographic determination of the apparent grain size" 


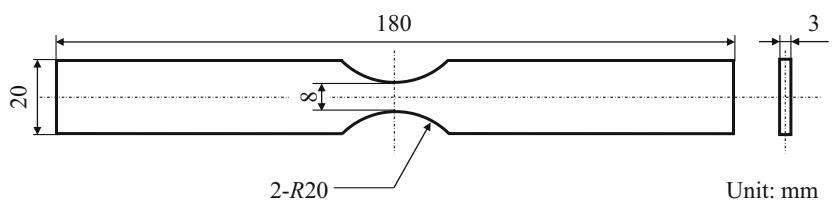

Fig. 3 Geometry of the employed specimen fabricated from the material after solution heat treatment

temperature change due to dissipated energy $\left(\Delta T_{\mathrm{D}}\right)$ can be obtained as a temperature component with a frequency twice as high as that of the load signal by the lock-in algorithm [17, 25] using eq. (1).

$\Delta T_{D}=2 \sqrt{\left\{\frac{2}{N} \sum_{t=1}^{N} T(t) \sin \left(2 \omega \frac{t}{f_{\text {rate }}}\right)\right\}^{2}+\left\{\frac{2}{N} \sum_{t=1}^{N} T(t) \cos \left(2 \omega \frac{t}{f_{\text {rate }}}\right)\right\}^{2}}$

Where $N$ is the total processing frame number, $t$ is the frame number, $T$ is the time-series temperature change, $\omega$ is the angular frequency of the load signal, and $f_{\text {rate }}$ is the frame rate.

Irreversible heat generation is a part of energy dissipation. Since $\Delta T_{\mathrm{D}}$ is the same as irreversible heat generation, $\Delta T_{\mathrm{D}}$ is defined as dissipated energy.

\section{Experimental Conditions}

\section{Specimen}

A type of 316L austenitic stainless steel (SUS316L) plate with the chemical composition given in Table 1 was subjected to solution heat treatment. The mechanical properties of the heattreated material (listed in Table 2) were obtained from tensile testing in accordance with JIS Z 2241:2011 "Metallic materials-Tensile testing-Method of test at room temperature." A typical micrograph of the heat-treated
Table 3 Specifications of the infrared camera used in this study

\begin{tabular}{cccc}
\hline Sensor type & Pixel resolution & Spectral range & NETD $^{\mathrm{a}}$ \\
\hline MCT & $320 \times 256$ & $7.7-9.3 \mu \mathrm{m}$ & $<25 \mathrm{mK}$
\end{tabular}

${ }^{\text {a }}$ Noise equivalent temperature difference.

material is shown in Fig. 2. The average grain size was determined as $123 \mu \mathrm{m}$, in accordance with JIS G 0551:2005 "Steels-Micrographic determination of the apparent grain size." The specimen employed in fatigue testing was fabricated to the geometry shown in Fig. 3 after solution heat treatment. This specimen geometry is almost the same as in Refs. $[7,17]$.

The faces and neck of the specimen employed in fatigue testing were polished with several grades of emery papers up to $\# 1500$ and then buffed. To remove the work hardened layer generated by polishing, an electro-polishing process was applied using a solution of phosphoric acid and ethanol in a ratio of 7: 3 .

\section{Experimental Setup}

Schematic illustrations of the experimental setup and measurement areas of an infrared camera (FLIR Systems, Inc., SC7300L) and strain gauge are shown in Fig. 4. The timeseries temperature change of the specimen surface subjected to cyclic loading was measured at room temperature using the infrared camera (Fig. 4 (a)). The surface of the specimen was coated with a flat paint to improve its thermal emissivity (Fig. 4 (b)). Some portions of the paint were removed to create markers for the purpose of motion compensation preprocessing (described in section Motion Compensation and Smoothing Filter). The specifications of the infrared camera used in this study are listed in Table 3. The field of view was adjusted to cover the narrowest portion of the specimen. A close-up lens was attached to the infrared camera, giving a spatial resolution for infrared thermography of approximately $38 \mu \mathrm{m}$ per pixel. This spatial resolution is sufficiently smaller
Fig. 4 Schematic illustrations of the experimental setup and measurement areas of infrared camera and strain gauge

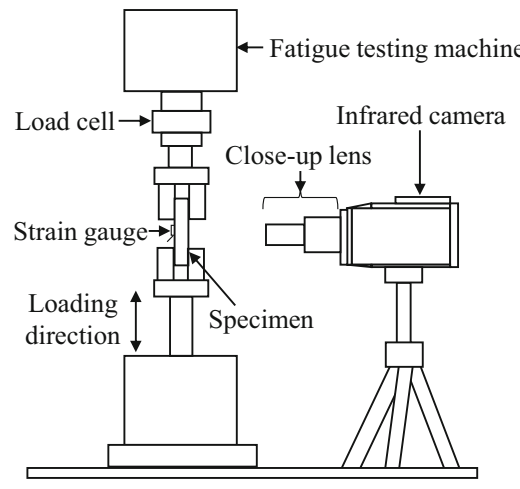

(a) Experimental setup

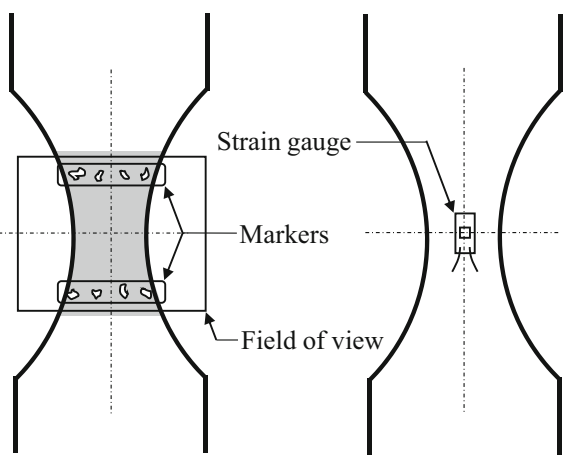

(b) Measurement area of infrared camera (c) Measurement area of strain gauge 


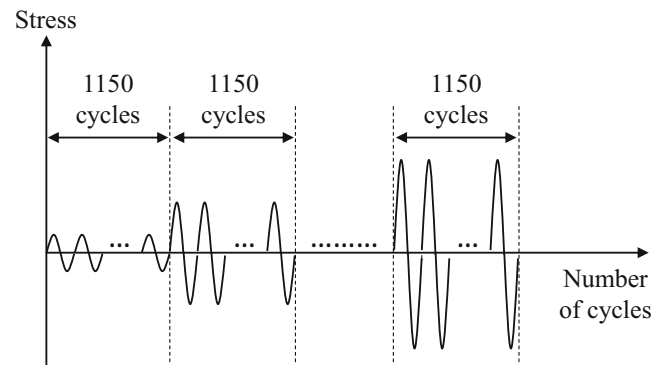

Fig. 5 Schematic illustration of the applied cyclic load during "staircaselike" stress level testing

than that of the average grain size of the material after solution heat treatment (123 $\mu \mathrm{m}$, shown in Fig. 2). The frame rate and recording time were set to $211 \mathrm{~Hz}$ and $10 \mathrm{~s}$, respectively, giving the time-series temperature change of the specimen surface over 2110 frames. The value of dissipated energy was calculated from the acquired frames using the procedure described in section Temperature Changes Due to Thermoelastic Effect and Dissipated Energy. The strain was measured on the opposite side of the specimen to the temperature measurement using a strain gauge with a gauge length of $1 \mathrm{~mm}$, as shown in Fig. 4 (c). The plastic strain energy was calculated from an area of hysteresis loop obtained from the strain gauge and load cell signals.

\section{Testing Conditions}

Fully reversed cyclic axis loading (stress ratio: $R=-1$ ) was applied to the specimen using an electrohydraulic fatigue testing machine with a loading capacity of $\pm 50 \mathrm{kN}$ (Saginomiya Seisakusho, Inc., FT-5). The waveform and frequency of the loading were set to sinusoidal and $5 \mathrm{~Hz}$, respectively. The applied stress amplitude $\left(\sigma_{\mathrm{a}}\right)$ was increased in steps, which is known as "staircase-like" stress level testing [17]. At each step, 1150 loading cycles shown in Fig. 5 were applied to the specimen. The temperature and strain at each stress amplitude were measured after every 1000 cycles.

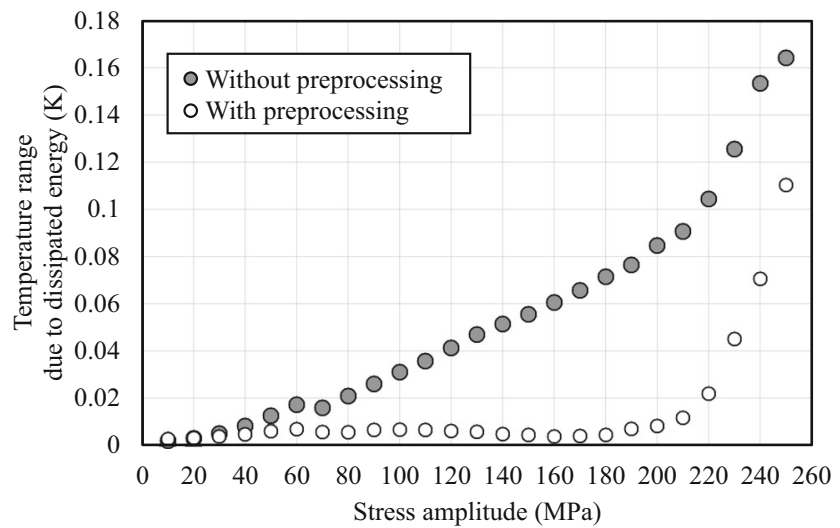

Fig. 6 Change in temperature range due to dissipated energy with stress amplitude. Preprocessing refers to image processing prior to calculations consisting of motion compensation and a smoothing filter

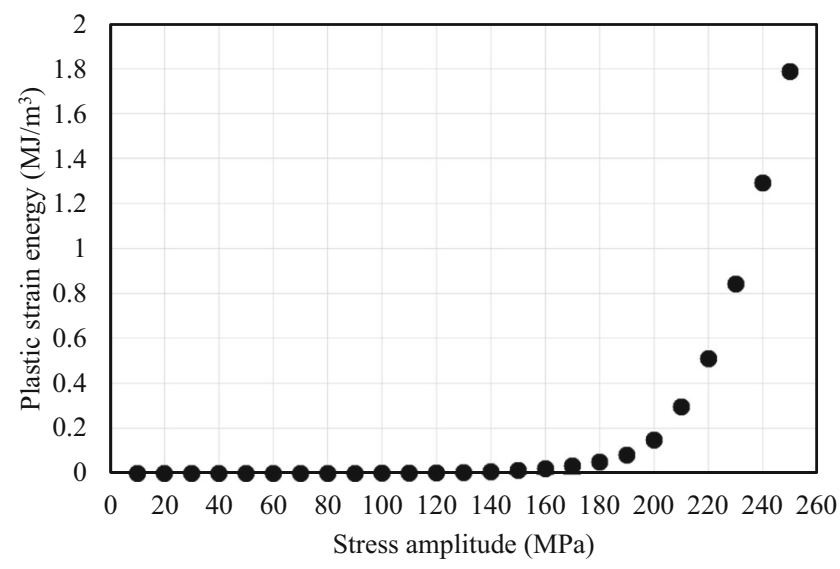

Fig. 7 Change in plastic strain energy with stress amplitude

\section{Motion Compensation and Smoothing Filter}

To appropriately measure the temperature of the specimens under loading, motion compensation was performed on the acquired time-series temperature images before the calculation of dissipated energy, to allow the displacement of the target specimen to be followed. A block matching algorithm with a sum of squared difference (SSD) criterion was utilized. The minimization of SSD criterion by parabola fitting [41] yielded displacement compensation of the target specimen in subpixel units. To further enhance the image detection, a smoothing filter with a $3 \times 3$ square kernel was applied to each frame prior to the motion compensation.

\section{Results and Discussion}

\section{Effect of Image Preprocessing on Dissipated Energy Measurements}

During the staircase-like stress level test (ranging from $\sigma_{\mathrm{a}}=10$ to $250 \mathrm{MPa}$ with a constant increment of $\sigma_{\mathrm{a}}=10 \mathrm{MPa}$ ), the dissipated energy and plastic strain energy at each stress amplitude were measured and plotted against the applied stress amplitude. The change in dissipated energy is shown in Fig. 6. Figure 6 also demonstrates the effect of image preprocessing consisting of the motion compensation and smoothing filter. The dissipated energy was taken as the average value of a $1.0 \mathrm{~mm}(\mathrm{~L}) \times 1.1 \mathrm{~mm}(\mathrm{~W})$ area at the center of the specimen. Without preprocessing, the dissipated energy was observed to increase gradually as the stress amplitude increased, beginning from a low stress amplitude. On the other hand, with preprocessing, the dissipated energy was observed to be almost constant at a low stress amplitude, until it showed a significant increase at around $\sigma_{\mathrm{a}}=200 \mathrm{MPa}$. The change in plastic strain energy during the same test is shown in Fig. 7. By comparing Figs. 6 and 7, it can be seen that the change in plastic strain energy is similar to the change in dissipated 


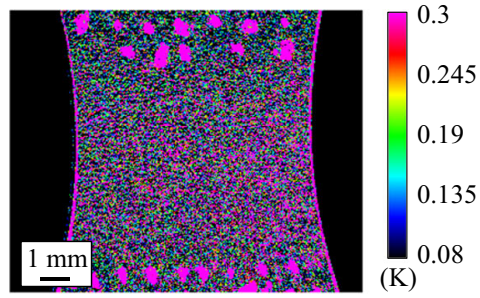

(a) Without preprocessing

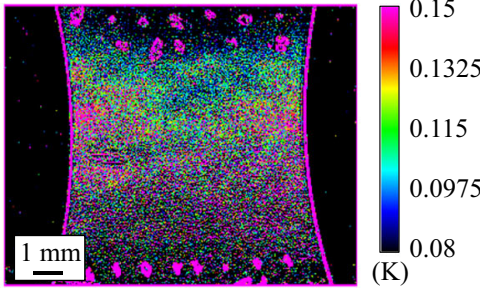

(b) With motion compensation

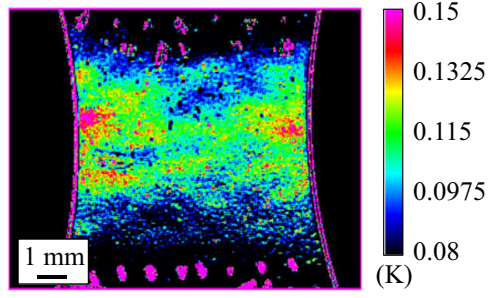

(c) With motion compensation and smoothing filter

Fig. 8 Effect of the motion compensation and smoothing filter on distribution of temperature range due to dissipated energy $\left(\sigma_{\mathrm{a}}=250 \mathrm{MPa}, N / N_{\mathrm{f}}=\right.$ 0.098)
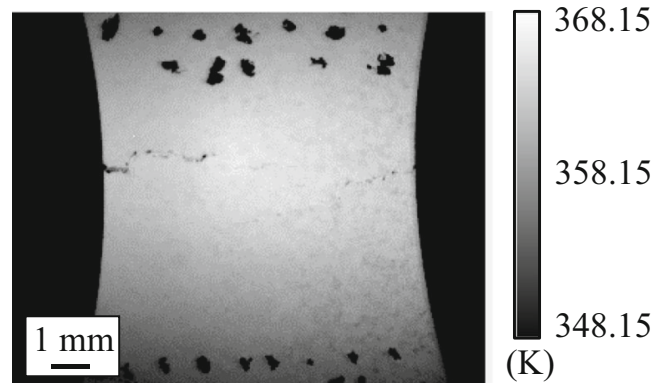

Fig. 9 Distribution of surface temperature $\left(\sigma_{\mathrm{a}}=250 \mathrm{MPa}, N / N_{\mathrm{f}}=0.98\right)$

energy with preprocessing. Indeed, the dissipated energy measured for type $316 \mathrm{~L}$ austenitic stainless steel specimen exhibits a strong correlation with the plastic strain energy [7]. However, the values of dissipated energy without preprocessing are far higher than those with preprocessing. It was considered that this "fake" temperature change due to displacement of the specimen could be measured to obtain the "fake" dissipated energy. The actual value of dissipated energy can be obtained by preprocessing the images with motion compensation and a smoothing filter.

The effect of preprocessing on the measured distribution of dissipated energy is shown in Fig. 8. Without preprocessing, the values of dissipated energy were randomly distributed on the specimen surface (Fig. 8 (a)). On the other hand, with motion compensation, the dissipated energy values were smaller (Fig. 8 (b)), although with higher
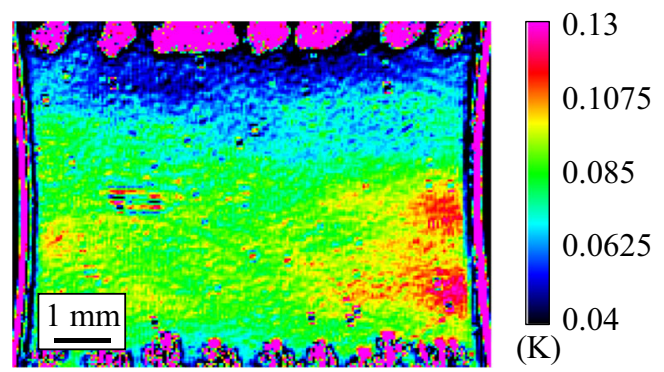

Fig. 10 Distribution of the temperature range due to dissipated energy with preprocessing $\left(\sigma_{\mathrm{a}}=240 \mathrm{MPa}\right)$ values around the notch root of the specimen. Furthermore, when both the motion compensation and smoothing filter were applied, several hot spots with significantly high dissipated energy values were clearly observed around the notch root (Fig. 8 (c)). After the measurement of dissipated energy shown in Fig. 8, the same stress amplitude was applied to the specimen to confirm the location of the fatigue failure. The number of cycles to failure of this specimen was $N_{\mathrm{f}}=1.02 \times 10^{4}$ cycles. The surface temperature distribution at $N=1.0 \times 10^{4}$ cycles is shown in Fig. 9. The main crack initiation was observed at the left-side notch root, with a second crack initiation at the right-side notch root. By comparing Figs. 8 (c) and 9, it was found that the hot spot sites with significantly high values of dissipated energy were in favorable agreement with the fatigue crack initiation locations. Consequently, the location of fatigue crack initiation can be accurately assessed by measuring the dissipated energy with high spatial resolution, assuming suitable image preprocessing is performed.

\section{Relationship between Dissipated Energy and Slip Bands}

The activity of slip bands results in fatigue crack initiation. The number of slip bands can be considered to show the activity of slip bands in the measured area. In this section, the

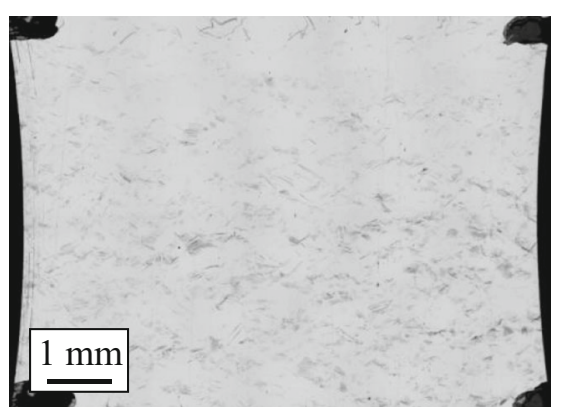

Fig. 11 Optical image of the slip bands on the specimen surface after the dissipated energy measurement shown in Fig. 10 


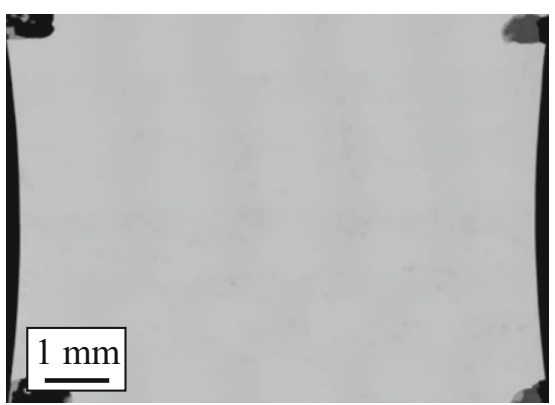

Fig. 12 Background image

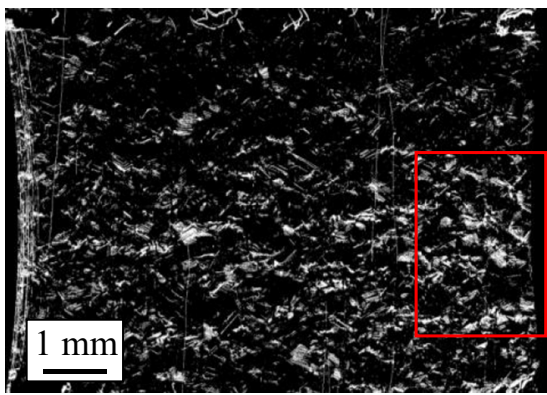

Fig. 13 Binary image of the slip bands

relationship between dissipated energy and slip bands during staircase-like stress level testing was investigated. After the staircase-like stress level test (ranging from $\sigma_{\mathrm{a}}=150$ to $240 \mathrm{MPa}$ with a constant increment of $\sigma_{\mathrm{a}}=10 \mathrm{MPa}$ ), the specimen was removed from the fatigue testing machine. The paint that was coated on the specimen surface was removed, and then the slip bands were observed using a digital microscope (Hirox Co., Ltd., KH-1300), on the same side of the specimen as the dissipated energy measurement. As in Fig. 6, a similar change in dissipated energy with increasing stress amplitude was also confirmed in this section. The distribution of dissipated energy at $\sigma_{\mathrm{a}}=240 \mathrm{MPa}$ and an optical image of the slip bands on the specimen surface are shown in Figs. 10 and 11, respectively. The preprocessing described in section Motion Compensation and Smoothing Filter was applied prior to the dissipated energy measurement. As shown in Fig. 10, two hot spots with significantly high dissipated energy values were confirmed at the right-side notch root. As shown in Fig. 11, numerous slip bands were observed on the specimen surface, with more slip bands at the right-side notch root than the left-side notch root.

To quantitatively evaluate the distribution of slip bands on the specimen surface, the number of slip bands in a certain area was counted by the following procedure. First, morphological image processing was applied to the original optical image of the specimen surface using commercially available image processing software (Matrox Electronic Systems Ltd., Inspector 9.0). The roughness, such as slip bands and scratches, were removed from the original image in this processing to form a background image, as shown in Fig. 12. The original image was then subtracted from the background image to obtain an image of the surface roughness, in which the slip bands are emphasized. Binarization processing was then applied to obtain the distribution of slip bands, as shown in Fig. 13. The threshold value in this binarization processing was set to be the brightness value of the scratches caused by polishing.

As an example, the original optical image and binary image of the slip bands in the area enclosed by the red rectangle in Fig. 13 are enlarged in Fig. 14; it was confirmed that the slip bands were suitably selected as the bright part.

To quantitatively evaluate the relationship between dissipated energy and slip bands, the notched area was

Fig. 14 Comparison between the original optical image and binary image of the slip bands

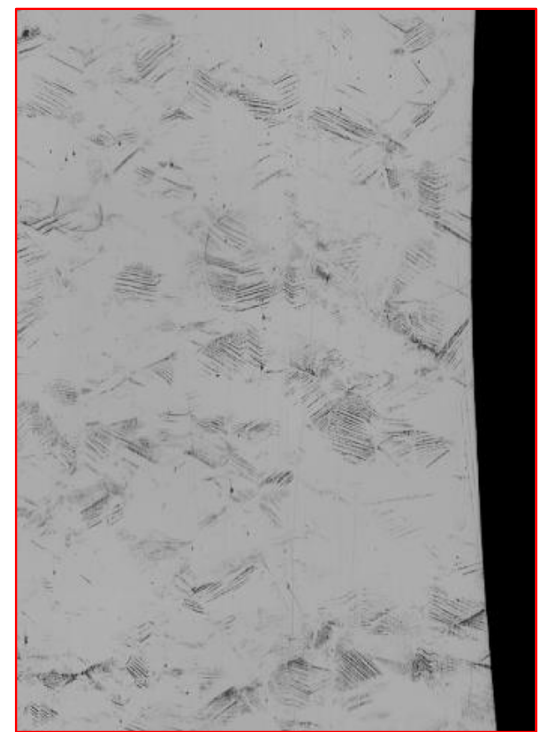

(a) Original optical image of the slip bands

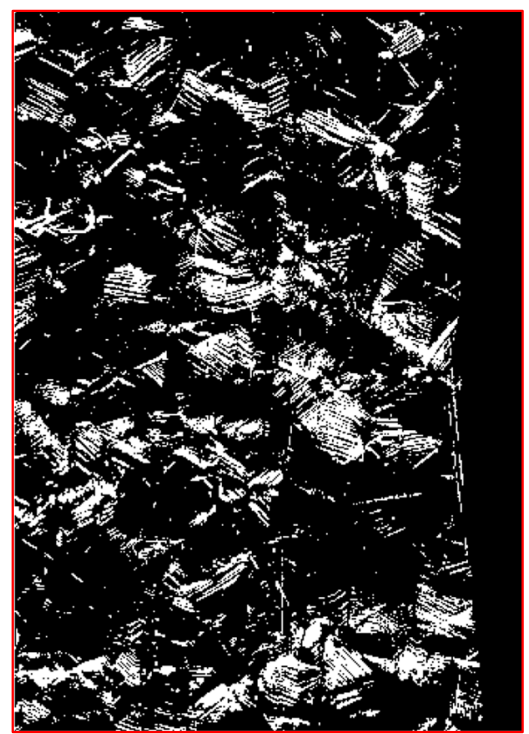

(b) Binary image of the slip bands 


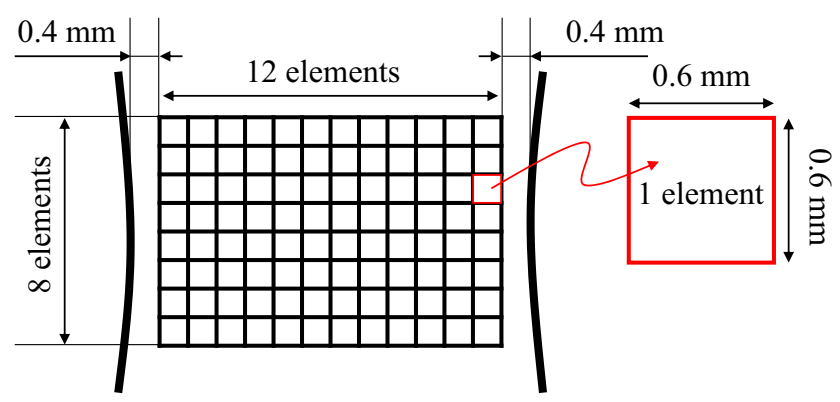

Fig. 15 Schematic illustration of evaluation area for dissipated energy and slip bands

divided into 96 evaluation elements, each with a square area of $0.6 \times 0.6 \mathrm{~mm}$, as shown schematically in Fig. 15 . Since the measured values of dissipated energy around the edge of the specimen were significantly influenced by various phenomena such as the edge effect, heat conduction, and convection, the evaluation area was set $0.4 \mathrm{~mm}$ inside the notch root. The relative area occupied by slip bands inside an element was defined as the slip-band-area ratio. The average value of dissipated energy determined for each element is plotted against the slip-band-area ratio in Fig. 16 (here, the solid line indicates the fitting line characterizing the relationship between these two parameters that was obtained by the least squares method). Hence, the dissipated energy correlated with the slip-band-area ratio, with a correlation coefficient of 0.789 . This correlation was confirmed with a total of three specimens including a qualitative evaluation. It was found that the magnitude of dissipated energy corresponded to the number of slip bands, which is related to slip band activity during cyclic loading. Indeed, crack initiation is also related to the behavior of slip bands [42]. Thus, it is considered that hot spots in the dissipated energy distribution indicate the active behavior of slip bands, which is related to the future crack initiation.

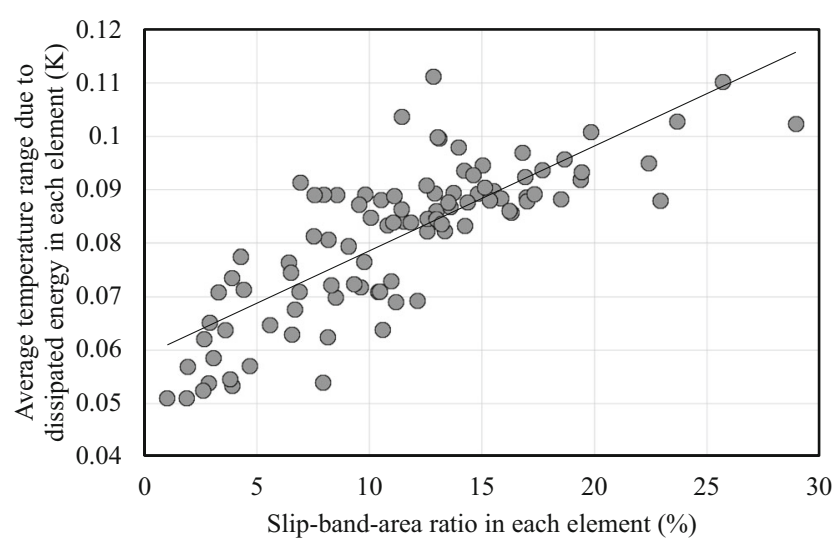

Fig. 16 Relationship between the average temperature range due to dissipated energy and slip-band-area ratio determined for each element. The solid line indicates the fitting line obtained by the least squares method

\section{Conclusions}

In this study, dissipated energy measurements with high spatial resolution were performed alongside slip bands observations for type $316 \mathrm{~L}$ austenitic stainless steel under fatigue loading. Notably, the analyses were performed on the same side of the specimen, allowing quantitative evaluation of the relationship between dissipated energy and slip bands in the same region and on the same scale. Following preprocessing of the time-series temperature change images using motion compensation and a smoothing filter, it was found that the change in plastic strain energy was similar to the change in dissipated energy. Moreover, the locations of fatigue crack initiation were accurately assessed from the distribution of dissipated energy. The slip bands were quantitatively evaluated by applying morphological image processing to the original optical image of slip bands on the specimen surface taken using a digital microscope. Owing to the positive correlation between the magnitude of dissipated energy and number of slip bands in a given area, it was suggested that regions of high dissipated energy were related to the active behavior of slip bands. Therefore, such regions could be used to predict the location of fatigue crack initiation.

Open Access This article is distributed under the terms of the Creative Commons Attribution 4.0 International License (http:// creativecommons.org/licenses/by/4.0/), which permits unrestricted use, distribution, and reproduction in any medium, provided you give appropriate credit to the original author(s) and the source, provide a link to the Creative Commons license, and indicate if changes were made.

\section{References}

1. Stromeyer CE (1914) The determination of fatigue limits under alternating stress conditions. Proc R Soc London A 90:411-425. https://doi.org/10.1098/rspa.1914.0066

2. Luong MP (1995) Infrared thermographic scanning of fatigue in metals. Nucl Eng Des 158:363-376. https://doi.org/10.1016/00295493(95)01043-H

3. La Rosa G, Risitano A (2000) Thermographic methodology for rapid determination of the fatigue limit of materials and mechanical components. Int J Fatigue 22:65-73. https://doi.org/10.1016/ S0142-1123(99)00088-2

4. Bremond P, Potet P (2001) Lock-in thermography: A tool to analyze and locate thermomechanical mechanisms in materials and structures. In: Proceedings of SPIE (Thermosense XXIII), March 2001, Orlando, Florida, USA, Vol. 4360, pp. 560-566. https://doi.org/10.1117/12.421039

5. Krapez J-C, Pacou D (2002) Thermography detection of damage initiation during fatigue tests. In: Proceedings of SPIE (Thermosense XXIV), March 2002, Orland, Florida, USA, Vol. 4710, pp. 435-449. https://doi.org/10.1117/12.459593

6. Irie Y, Inoue H, Mori T, Takao M (2010) Evaluation of fatigue limit of notched specimen by measurement of dissipated energy. Trans 
Jpn Soc Mech Eng A 76:410-412. https://doi.org/10.1299/kikaia. 76.410 [in Japanese]

7. Akai A, Shiozawa D, Sakagami T (2013) Dissipated energy evaluation for austenitic stainless steel. J Soc Mater Sci Jpn 62:554-561. https://doi.org/10.2472/jsms.62.554 [in Japanese]

8. Kordatos EZ, Dassios KG, Aggelis DG, Matikas TE (2013) Rapid evaluation of the fatigue limit in composites using infrared lock-in thermography and acoustic emission. Mech Res Commun 54:14 20. https://doi.org/10.1016/j.mechrescom.2013.09.005

9. Palumbo D, Galietti U (2014) Characterisation of steel welded joints by infrared thermographic methods. Quant InfraRed Thermogr J 11:29-42. https://doi.org/10.1080/17686733.2013. 874220

10. Akai A, Inaba K, Shiozawa D, Sakagami T (2015) Estimation of fatigue crack initiation location based on dissipated energy measurement. J Soc Mater Sci Jpn 64:668-674. https://doi.org/10. 2472/jsms.64.668 [in Japanese]

11. De Finis R, Palumbo D, Ancona F, Galietti U (2015) Fatigue limit evaluation of various martensitic stainless steels with new robust thermographic data analysis. Int J Fatigue 74:88-96. https://doi.org/ 10.1016/j.ijfatigue.2014.12.010

12. Wang XG, Crupi V, Jiang C, Guglielmino E (2015) Quantitative thermographic methodology for fatigue life assessment in a multiscale energy dissipation framework. Int J Fatigue 81:249 256. https://doi.org/10.1016/j.jpfatigue.2015.08.015

13. Guo S, Zhou Y, Zhang H, Yan Z, Wang W, Sun K, Li Y (2015) Thermographic analysis of the fatigue heating process for AZ31B magnesium alloy. Mater Des 65:1172-1180. https://doi.org/10. 1016/j.matdes.2014.08.052

14. Plekhov O, Naimark O, Narykova M, Kadomtsev A, Betechtin V (2016) Study of dissipation properties and structure evolution in metals with different grain size under HCF and VHCF loadings. Procedia Struct Integr 2:2084-2090. https://doi.org/10.1016/j. prostr.2016.06.261

15. Palumbo D, De Finis R, Demelio PG, Galietti U (2016) A new rapid thermographic method to assess the fatigue limit in GFRP composites. Composites B 103:60-67. https://doi.org/10.1016/j. compositesb.2016.08.007

16. Yang H, Cui Z, Wang W, Xu B, Xu H (2016) Fatigue behavior of AZ31B magnesium alloy electron beam welded joint based on infrared thermography. Trans Nonferrous Met Soc China 26:25952602. https://doi.org/10.1016/S1003-6326(16)64385-6

17. Shiozawa D, Inagawa T, Washio T, Sakagami T (2017) Accuracy improvement in dissipated energy measurement by using phase information. Meas Sci Technol 28:044004. https://doi.org/10. 1088/1361-6501/28/4/044004

18. Kawai R, Yoshikawa T, Kurokawa Y, Irie Y, Inoue H (2017) Rapid evaluation of fatigue limit using infrared thermography: Comparison between two methods for quantifying temperature evolution. Mech Eng J 4:17-00009. https://doi.org/10.1299/mej. 17-00009

19. Hayabusa K, Inaba K, Ikeda H, Kishimoto K (2017) Estimation of fatigue limits from temperature data measured by IR thermography. Exp Mech 57:185-194. https://doi.org/ 10.1007/s11340-016-0221-7

20. Chhith S, De Waele W, De Baets P (2018) Rapid determination of fretting fatigue limit by infrared thermography. Exp Mech 58:259267. https://doi.org/10.1007/s11340-017-0340-9

21. Katunin A, Wachla D (2019) Determination of fatigue limit of polymeric composites in fully reversed bending loading mode using self-heating effect. J Compos Mater 53:83-91. $10.1177 \% 2 \mathrm{~F} 0021998318780454$

22. Yang W, Guo X, Guo Q, Fan J (2019) Rapid evaluation for highcycle fatigue reliability of metallic materials through quantitative thermography methodology. Int J Fatigue 124:461-472. https://doi. org/10.1016/j.ijfatigue.2019.03.024
23. Huang J, Pastor ML, Garnier C, Gong XJ (2019) A new model for fatigue life prediction based on infrared thermography and degradation process for CFRP composite laminates. Int J Fatigue 120: 87-95. https://doi.org/10.1016/j.ijfatigue.2018.11.002

24. Ricotta M, Meneghetti G, Atzori B, Risitano G, Risitano A (2019) Comparison of experimental thermal methods for the fatigue limit evaluation of a stainless steel. Metals 9:677. https://doi.org/10. 3390/met9060677

25. Sakagami T, Kubo S, Tamura E, Nishimura T (2005) Identification of plastic-zone based on double frequency lock-in thermographic temperature measurement. In: Proceedings of the $11^{\text {th }}$ International Conference on Fracture (ICF 11), March 2005, Turin, Italy

26. Inoue H (2011) Rapid evaluation of fatigue limits using infrared thermography. J Jpn Soc Non-Destr Insp 60:322-327 [in Japanese]

27. Yang B, Liaw PK, Wang H, Jiang L, Huang JY, Kuo RC, Huang JG (2001) Thermographic investigation of the fatigue behavior of reactor pressure vessel steels. Mater Sci Eng A 314:131-139. https:// doi.org/10.1016/S0921-5093(00)01910-9

28. Jiang L, Wang H, Liaw PK, Brooks CR, Klarstrom DL (2001) Characterization of the temperature evolution during high-cycle fatigue of the ULTIMET superalloy: Experiment and theoretical modeling. Metall Mater Trans A 32:2279-2296. https://doi.org/ 10.1007/s11661-001-0203-x

29. Ly HA, Inoue H, Irie Y (2011) Numerical simulation on rapid evaluation of fatigue limit through temperature evolution. J Solid Mech Mater Eng 5:459-475. https://doi.org/10.1299/jmmp.5.459

30. Boulanger T, Chrysochoos A, Mabru C, Galtier A (2004) Calorimetric analysis of dissipative and thermoelastic effects associated with the fatigue behavior of steels. Int J Fatigue 26:221-229. https://doi.org/10.1016/S0142-1123(03)00171-3

31. Morabito AE, Chrysochoos A, Dattoma V, Galietti U (2007) Analysis of heat sources accompanying the fatigue of 2024 T3 aluminium alloys. Int J Fatigue 29:977-984. https://doi.org/10. 1016/j.ijfatigue.2006.06.015

32. Berthel B, Chrysochoos A, Wattrisse B, Galtier A (2008) Infrared image processing for the calorimetric analysis of fatigue phenomena. Exp Mech 48:79-90. https://doi.org/10. 1007/s11340-007-9092-2

33. Bodelot L, Sabatier L, Charkaluk E, Dufrénoy P (2009) Experimental setup for fully coupled kinematic and thermal measurements at the microstructure scale of an AISI 316L steel. Mater Sci Eng A 501:52-60. https://doi.org/10.1016/j. msea.2008.09.053

34. Wang X, Witz J-F, El Bartali A, Oudriss A, Jiang C (2015) Quantitative infrared thermography applied to subgrain scale and the effect of out-of-plane deformation. Infrared Phys Technol 71: 432-438. https://doi.org/10.1016/j.infrared.2015.06.003

35. Bodelot L, Sabatier L, Charkaluk E, Dufrénoy P (2009) Experimental determination of fully-coupled kinematical and thermal fields at the scale of grains under cyclic loading. Adv Eng Mater 11:723-726. https://doi.org/10.1002/adem.200900035

36. Cugy P, Galtier A (2002) Microplasticity and temperature increase in low carbon steels. In: Proceedings of the Eighth International Fatigue Congress (Fatigue 2002), June 2002, Stockholm, Sweden, pp. $549-556$

37. Wang C, Blanche A, Wagner D, Chrysochoos A, Bathias C (2014) Dissipative and microstructural effects associated with fatigue crack initiation on an Armco iron. Int J Fatigue 58:152-157. https://doi. org/10.1016/j.ijfatigue.2013.02.009

38. Shiozawa D, Inaba K, Akai A, Sakagami T (2014) Experimental study of relationship between energy dissipation and fatigue damage from observation of slip band by atomic force microscope. Adv Mater Res 891-892:606-611. https://doi.org/10.4028/www. scientific.net/AMR.891-892.606 
39. Shiozawa D, Akai A, Inaba K, Sakagami T (2016) Relationship between dissipated energy and growth behavior of slip bands in austenitic stainless steel. In: Proceedings of the $10^{\text {th }}$ Asia-Pacific Conference on Fracture and Strength (APCFS 2016), September 2016, Toyama, Japan, pp. 223-224

40. Enke NF, Sandor BI (1988) Cyclic plasticity analysis by differential infrared thermography. In: Proceedings of the VI International Congress on Experimental Mechanics, June 1988, Portland, Oregon, USA, pp. 836-842

41. Sakagami T, Matsumoto T, Kubo S, Sato D (2009) Nondestructive testing by super-resolution infrared thermography. In: Proceedings of SPIE (Thermosense XXXI), April 2009, Orland, Florida, USA, Vol. 7299. https://doi.org/10.1117/12.821167

42. Nakai Y (2001) Evaluation of fatigue damage and fatigue crack initiation process by means of atomic-force microscopy. Mater Sci Res Int 7:73-81. https://doi.org/10.2472/jsms.50.6Appendix_73

Publisher's Note Springer Nature remains neutral with regard to jurisdictional claims in published maps and institutional affiliations. 